Noname manuscript No.

(will be inserted by the editor)

\title{
The provision and utility of earth science to decision-makers: synthesis and key findings
}

\author{
Mark C. Quigley · Luke G. Bennetts • \\ Patricia Durance - Petra M. Kuhnert . \\ Mark D. Lindsay · Keith G. Pembleton . \\ Melanie E. Roberts . \\ Christopher J. White
}

Received: date / Accepted: date

\begin{abstract}
This paper synthesizes important elements from case studies presented in its companion paper (Quigley et al., 2019) to define mutual and distinct characteristics and to develop a more holistic understanding of how earth science was used to support diverse examples of decision-making. We identify a suite of 28 different science actions used within the case studies that
\end{abstract}

Mark C. Quigley

School of Earth Sciences, University of Melbourne, Parkville, VIC 3010, Australia

Department of Geological Sciences, University of Canterbury, Christchurch, New Zealand

E-mail: mark.quigley@unimelb.edu.au

Luke G. Bennetts

School of Mathematical Sciences, University of Adelaide, Adelaide, SA 5005, Australia

Patricia Durance

GNS Science, 1 Fairway Drive, Lower Hutt 5010, New Zealand

Petra M. Kuhnert

CSIRO Data61, GPO Box 1700, Canberra, ACT, Australia

Mark D. Lindsay

Centre for Exploration Targeting, School of Earth Sciences, University of Western Australia, Crawley, WA 6009, Australia

Keith G. Pembleton

School of Agricultural, Computational and Environmental Sciences and Centre for Sustainable Agricultural Systems, University of Southern Queensland, Toowoomba, QLD 4350, Australia

Melanie E. Roberts

Australian Rivers Institute, Griffith University, Nathan, QLD 4111, Australia School of Mathematics and Statistics, University of Melbourne, Parkville, VIC 3010, Australia

Christopher J. White

School of Engineering, University of Tasmania, Hobart, TAS 7005, Australia

Department of Civil and Environmental Engineering, University of Strathclyde, Glasgow, UK 
are classified as pertaining to: (i) evidence acquisition and analysis, (ii) provision of science to target audience, or (iii) enhancing future science provision and utility. Sample action pathways provide empirically-evidenced, albeit simplified, examples of how scientists may contribute to the progression of science through complex decision-making frameworks. Decision trees with multiple scientific and non-scientific inputs are presented based on empirical evidence and theory to provide scientists and decision-makers with simplified examples of complex multi-stepped decision-making processes under conditions of risk and uncertainty. Evidence for nonlinear engagement between decision-makers and science providers is presented, including non-traditional approaches such as provision of unsolicited science through the media and stake-holders. Examples of scientically-informed, precautionary decision-making with adaptive capacity, even where more economically-favourable decision alternatives exist, are provided. We undertake a self-elicitation exercise of case studies to derive values and uncertainties for $\%$ scientific agreement amongst utilized inputs and \% uptake of potentially-relevant and available science. We observe a tendency towards increased scientific uptake with increasing scientific agreement, but this is not ubiquitous; politically-affected decisions and/or complex multi-decision scenarios under time pressure complicate this relationship. An increasing need for decision-making expediency that is not met by increased availability of relevant science evidence may rely on expert-judgement based on incomplete knowledge that is manifested as large uncertainties in defining a singular value for scientific agreement and uptake. We encourage scientists to further document their experiences using the science action classification scheme provided herein to stimulate further comparative analyses of this nature.

Keywords Earth science $\cdot$ policy $\cdot$ decision-making $\cdot$ natural disasters

\section{Introduction}

Scientists are increasingly motivated to provide scientific evidence to decisionmakers. This is clear from calls to appoint and increase the involvement of science advisors in decision-making processes (Doubleday and Wilsdon 2012 Gluckman, 2014, Schaal, 2017), contemporary research aimed at improving communications of science and scientific uncertainty to decision-makers (Fischoff and Davis, 2014, Aspinall, 2010), improving elicitations of expert science advice (Aspinall , 2010), and understanding science communicator priority objectives and behaviors (Dudo and Besley, 2016, Nisbet and Markowitz 2015). Academic institutions are being encouraged to facilitate better dialogue amongst scientists and decision-makers (Whitmer et al., 2010), and some are responding by establishing specific programs with this purpose. Moreover, there is a growing corpus of peer-reviewed literature describing how scientific

\footnotetext{
1 Notably, Winton Centre for Risk and Evidence Communication, Cambridge University, UK, https://medium.com/wintoncentre Institute for Risk and Uncertainty, University of Liverpool, UK, https://www.liverpool.ac.uk/risk-and-
} 
evidence can contribute to policy, emergency, and other types of decisionmaking (Gluckman, 2014: Brownson et al., 2009; Foster et al., 2000 Seeger, 2006; Gluckman, 2016, Langer et al., 2016), and provide data and knowledge to facilitate "Dynamic Adaptive Policy Pathways" for decision-making in cases of high uncertainty (Haasnoot et al., 2013).

The above actions do not guarantee a more prominent role for science in decision-making. Nor does the provision of science to decision-makers ensure decisions will align with prevailing scientific evidence. Decision-making often requires consideration of fiscal, cultural, and political inputs and personal values and beliefs (Krupnick et al., 2006, Nutbeam and Boxall, 2008), some of which may not be amendable to objective analysis (Gillieson, 2004 Karr, 2006 Lorenzoni et al., 2007). Non-scientific inputs may be prioritized even if decision-makers understand the nature and value of the contributing science (Sutherland et al., 2013). Initial proposals to reduce science funding (Reardon et al., 2017) and attempts to devalue the role of science (Mervis, 2017) suggest that not all leaders seek an increasing role for science in decision-making. Base knowledge, experience, context and potential bias of the decision-makers may influence how science is interpreted (Frodeman, 1995). A need for expediency or imposed fiscal constraints may require decisions to be made without consideration of potentially relevant inputs, including scientific information. Uncertainties inherent in decision-making can include scenarios that pose significant risks to human life, infrastructure, and environment. Further, perceived immediate risks may need to be addressed without considering all potentiallyrelevant scientific evidence. The temporal context of decision-making may necessitate use of pre-existing protocols and science advisors, or provide time to develop existing or new relationships, Scientists with knowledge and/or expertise relevant to decision-making may not know who to contact, how to contact them, or what to say.

Here we present evidence from seven case studies (described in detail in a companion paper; Quigley et al., 2019), in which the authors have been participants in and/or possess knowledge of the processes by which science was provided to and utilized by decision-makers. These case studies are drawn from the experiences of the authors. To facilitate a broad range of perspectives and to prevent bias in the selection of case studies from limiting the conclusions in this study, we established no a priori criteria for including or excluding case studies. The insights elicited from these case studies are drawn from the experiences of scientists working across a range of disciplines who came together as part of the 2016 Theo Murphy High Flyers Think Tank: An interdisciplinary approach to living in a risky world (refer to Colyvan et al. (2017) for further details). These case studies, written from the perspective of scientists engaged in the communication of science to decision makers, illustrates both common elements to communication as well as highlighting the diversity in science communications and decisions outcomes required for different scenarios. We

uncertainty; Mitchell Centre for Sustainability Solutions, University of Maine, USA, https://umaine.edu/mitchellcenter/ Program on Science in the Public Interest, Georgetown University, USA, https://spi.georgetown.edu 
acknowledge that the inclusion of additional or alternative case studies may elicit additional (or different) conclusions.

We (i) define the science providers, decision-makers, and science provision actions involved in the case studies, (ii) identify and classify diverse scientific actions contributing to the decision-making, and (iii) develop empiricallyevidenced and theoretical decision trees, and use them to illustrate how earth science inputs inform decision-making. The extent to which decisions aligned with prevailing science evidence is compared with qualitative estimates of the volume and scientific consensus of the contributed science. Our work builds upon lessons learned from prior analyses of case studies (e.g. Gluckman, 2014 Pielke Jr and Conant, 2003): (1) science provides only one of many relevant components in the process of decision-making; (2) predictions drawn from scientific inputs should not be conflated with policy; and (3) many scientific products are difficult to evaluate and easy to misuse. Further, scientific inputs may have varying levels of accuracy, sophistication, and experience that are not always well described and considered in decision-making (Pielke Jr, 2003).

Our work offers empirical examples to supplement a rich volume of literature on how science may contribute to decision-making in conditions involving risk and uncertainty. Relevant literature includes treatises on decision theory (North, 1968: Varis, 1997, White, 2018), risk governance and management (Aven and Renn, 2010 Van Asselt and Renn, 2011), and science-policy models informed by analyses of boundary organizations, knowledge systems and integrated scientific assessments (Kirchhoff et al., 2013 Cash et al., 2006, Feldman 2009). Prior research has described how earth science may best contribute to decision-making in the fields of climate science (see Dilling and Lemos, 2011, and references therein) and emergency and disaster management (Kapucu and Garayev, 2011; Zhou et al. 2018). Central conclusions drawn from many studies are that (1) the loading-dock model for science provision is unlikely to be successful (i.e., scientists prepare models, products, forecasts or other information for general use, without consulting with, or understanding the needs of, potential end users, and with the expectation that the information provided will still be useful; see, e.g., Cash et al., 2006); (2) the establishment of multidisciplinary and collaborative knowledge networks of policy makers, scientists, government agencies, and nongovernmental organizations may broaden and diversify communication pathways and decision spaces, and increase reliability, credibility, and trust, to the collective benefit of decision-making (Feldman, 2009); and (3) boundary organizations may stabilize and increase the efficiency of science knowledge and product delivery to stakeholders and decision-makers (e.g. Kirchhoff et al. 2013).

\subsection{Definitions}

Before we begin our analysis of the case studies described in Quigley et al. (2019), we shall clarify our identities and perspectives. Collectively, we are "science providers", herein identified as university, government or industry sci- 
entists, who are the creators and/or possessors of a specifically-defined quanta of data, knowledge, and/or expertise (herein referred to as science, scientific information, science provisions, data, models, or expertise), which we have directly or indirectly (via another science provider) communicated to "decision makers" (see Table1 in 3.1). The scope of this paper is limited to the physical earth and agricultural sciences; other fields of science (e.g. social, political and economic sciences) are relevant to many of the case studies examined but not evaluated in this paper. The identities of decision-makers in this study are limited to individuals or collectives of individuals within governmental agencies, emergency response agencies, committees, infrastructure providers, industries and businesses (Table 1) who are specifically tasked with making strategic and/or operational decisions using affective and analytical processes (Doyle and Paton (2018)). A "stakeholder" is used to describe any actor (institution, group or individual) with an interest or a role to play in a decision-making process. In a broad sense, we recognize that many individuals may have shared identities as science-providers, decision-makers, and stakeholders in a variety of contexts (e.g., a scientist may have a vested interest or role in a decisionmaking outcome, a scientist may make decisions as to whether to research a given theme and how to conduct this research) however the level of specificity applied to these definitions of these groups herein attempts to limit this overlap.

The processes by which science is acquired and communicated to decisionmakers are described using a series of science actions that we classify as pertaining to (i) the acquisition and analysis of scientific information, (ii) the provision of science, and (iii) the support of science utility (see Figure 1 in 3.2. . We offer sample "science provision pathways" (Figure 1) that are drawn from our collective experiences, although these are not intended to represent the science provision and utility process as a linear or deficit model, but rather to provide a sample pathway whose "viability" is evidenced by our experiences.

We acknowledge that science providers needn't necessarily be scientists (e.g., political advocates, media, or policy makers), but in this study we deliberately limit our scope to our own experiences. Because all science provisions are accompanied by uncertainties (Table 1), and the diverse range of decisionmakers investigated herein have all, by definition, been responsible for selecting a decision from at least two distinct alternatives, then each decision-making process is accompanied by risks. The "risks considered" in Table1 1 refer only to those that include risks of fatality, injury, or other undesired personal health effects to a specified member or members of the general public, risks to personal wealth or business, risks to infrastructure, and/or risks to environment, including flora and fauna. They do not include such ubiquitous features of decision making as economic risks, political risks and public perception. Many of these latter risks are relevant to some of the case studies investigated herein, however we do not focus on their roles in this study. The consideration of science throughout the decision-making process is herein also referred to as the science uptake or utility by decision-makers. As a collective of earth scientists with expertise in scientific data acquisition, analysis, and communication, 
but with limited expertise in aspects of decision theory, science policy, and decision-making analysis, the primary motive of our study presented herein is to communicate our experiences in specific case studies. Formal training in decision theory is limited amongst scientists, which can limit their capacity to apply decision theory approaches to their communications with decision makers. By presenting communication approaches from the perspective of scientists, we expect our approach to resonate with other scientists, and provide an accessible framework from which to review and evaluate their own scientific communications to decision makers. The results presented herein may be further analysed by those with more expertise in decision theory and analysis.

\section{Case studies}

Case study S1 examines land-use zoning decisions in response to natural hazard impacts during the 2010-2011 Canterbury earthquake sequence in New Zealand and assessments of future risk. In response to calculated life safety risks from future rockfall and cliff collapse (case study S1a; Massey et al. 2014), the NZ central government-appointed Canterbury Earthquake Recovery Authority (CERA) made "red zone" purchase offers in June 2012 to owners of properties where the annual individual fatality risk estimated from modelling of future rockfall and cliff-collapse hazards and associated exposure and vulnerabilities was greater than or equal to "acceptable" thresholds of 1 in 10,000 years. Zoning decisions were independently reviewed and expanded upon from October to December 2011. Following review, a final total of 714 Port Hills properties were zoned red and Crown offers were made to their owners if they were insured ${ }^{2}$. Further opportunities were created for affected residents to challenge land-zone decisions. In response to liquefaction-induced land and property damage, CERA also purchased 7,346 red-zoned residential properties in greater Christchurch (case study S1b). The justification for liquefaction red zone decisions as stated by CERA was (i) significant and extensive area wide land damage had occurred, (ii) design, success and possible commencement of engineering solutions given ongoing seismic activity were uncertain, and (iii) repair would be disruptive and protracted for landowners. In reality, as disclosed in the "Brownlee paper" presented in confidence by the Minister for Earthquake Recovery to the New Zealand Cabinet ${ }^{3}$, the equation used to undertake red-zone decision-making drew fundamentally on economic inputs, although science and engineering experts were consulted in this process. Land use planning changes required development of a new Christchurch City Replacement District Plan prepared by the Christchurch City Council in collaboration with government, university and industry scientists. Some affected property owners appealed red-zone decisions in independent panel hearings.

2 See http://www.eqrecoverylearning.org/assets/downloads/res0052-land-zoning-policyand-the-residential-red-zone2.pdf

3 See https://ceraarchive.dpmc.govt.nz/sites/default/files/Documents/memorandumfor-cabinet-land-damage-june-2011_0.pdf 
Case study S2 examines decisions made by land holders around crop inputs and management in a developing agricultural region in Northern Queensland, Australia. It examines a particular case where a land holder posed a question regarding planting dates and irrigation management of a chickpea (Cicer arietinum L.) crop. As there were no experimental data for this region to base advice on, biophysical modelling was used to examine a range of cropping scenarios. The case study examines how the results of such analysis can be effectively communicated (along with the modelling uncertainty) beyond individual farm businesses to whole sectors of the agricultural industry.

Case study S3 examines the provision and receipt of flood forecasts during operational response, and challenges identified by both providers of scientific advice, and decision-makers reliant on the advice. Challenging aspects in the communication of flood forecasting include the absence of a standardised approach to communicating uncertainty (e.g., via error bounds) within flood forecasts.

Case study S4 details a scientist-led process undertaken for the 2016 Tasmanian State Natural Disaster Risk Assessment, which provided the emergency management sector and key Government decision-makers with riskbased information to help prepare for and reduce the impact of natural disasters, including bushfires, floods, severe storms, earthquakes, landslides, coastal inundations, heatwaves and influenza pandemics. The process relied on interdisciplinary cooperation and collaboration, as opposed to science communication only. The use of "confidence" ratings allowed for uncertainty in data or disagreement between experts to be taken into account during the analysis. However, the lack of provision to be able to combine expertise with confidence into a single communicable and reportable value was found to be a limiting factor.

Case study S5 examines the use of scientific evidence in an application made by a NZ-based company in 2014 for consent to mine phosphorite nodules in NZ's Exclusive Economic Zone. The application was unsuccessful, with the decision-making committee appointed by an Environmental Protection Authority citing concerns related to the impact of the drag-head on the seabed and the benthic fauna in and on the seabed. The committee concluded that there was likely to be significant and permanent damage to the benthic environment, modest economic benefits compared to environmental effects, and significant effect on the Benthic Protection Area, which overlapped with part of the permitted area.

Case study S6 examines the use of geological modelling in making informed decisions regarding exploration and extraction of resources. The use of models is widespread in minerals and petroleum industries, as they provide a representation of the subsurface, and indicate the location and volume of a resource. An example from the Gippsland Basin - a mature oil and gas producing region in southeastern Australia, and under study as a potential site location for CO2 sequestration - is presented, focussing on how model uncertainties are located and measured. A second example, describing the resource evaluation of a Canadian gold deposit, shows how scientific evidence (modelling) was 
used to downgrade the resources, rendering the deposit sub-economic, with economic impacts on the holding company.

Case study S7 investigates the challenges around pollutant load estimation and reporting for the Great Barrier Reef (GBR), noting that scientific uncertainty has recently been identified as an important component to GBR reporting in two external reviews, and discussions are underway to determine how best to quantify, interpret and communicate uncertainty for decisionmaking activities. It is noted that despite significant methodological advances in the quantification of pollutant loads and their uncertainties for the GBR to date, these approaches to uncertainty quantification have not made it into the GBR report card, nor have they been used in the prioritisation of catchments.

\section{Results}

3.1 Science providers, decision-makers and risks

Table 1 identifies the science providers, decision-makers and risks considered in each of the seven case studies, S1-S7. Science providers include government scientists (S1, S3-S7), university researchers (S1, S2, S4-S7), and industry scientists (S1, S2, S4-S7). Decision-makers include governmental agencies (S1, S3, S4), emergency response agencies (S3, S4), appointed committees (S1, $\mathrm{S} 5, \mathrm{~S} 7$ ), infrastructure providers (S1, S3, S4), and industries/businesses (S2, $\mathrm{S} 4, \mathrm{~S} 6)$. Some cases have multiple decision-makers because decision-making required iterative steps (S1) or a single decision-making process involved multiple working parties and decision-makers (S4). Enacted decisions relate to policy development with or without implementation (S1, S4, S5, S7), emergency management ( $\mathrm{S} 3, \mathrm{~S} 4)$, natural economic resource management (S4, S5, $\mathrm{S} 6$ ), and environmental protection (S2, S4, S5, S7). Considered risks include immediate endangerment of human life and safety (S1, S3, S4), infrastructure (S1, S4), environment (S1, S2, S4, S5, S7), food and biosecurity (S2, S4, S5, S7), and economy (S2, S4-S7).

Scientific information was solicited and considered by decision-makers in all cases. In some cases, science providers with relevant specific expertise and unique data were not initially solicited by decision-makers and/or acting science providers to participate in science provision actions (S1, S3, S4, S6). Reasons for this include decision-makers' unawareness that additional relevant science expertise and data existed (S1, S4), a lack of time, financial resources, and/or perceived need to seek the involvement of additional science providers during decision-making (S4), infeasibility of seeking additional science support due to the time-sensitive need to follow emergency protocols (S3), or confidential requirements of the decision-maker (S6). In five cases (S1, S2, S4S6), decision-makers ultimately considered relevant science that they did not initially solicit. Some of this was sourced through existing scientific literature by initially solicited science providers (S1,S2, S4-S6) and some entered into 


\begin{tabular}{|c|c|c|c|c|c|}
\hline Case study (\#) & Science providers & Decision-makers & Risks considered & $\begin{array}{c}\text { Solicited } \\
\text { science } \\
\text { considered? }\end{array}$ & \begin{tabular}{|c}
$\begin{array}{c}\text { Unsolicited } \\
\text { science } \\
\text { considered? }\end{array}$ \\
\end{tabular} \\
\hline $\begin{array}{c}\text { Land-use zoning in response } \\
\text { to the 2010-2011 } \\
\text { Canterbury earthquake } \\
\text { sequence (S1 a-rockfall, S1b- } \\
\text { liquefaction) }\end{array}$ & $\begin{array}{c}\text { Crown Research institutes, } \\
\text { university researchers, } \\
\text { industry scientists }\end{array}$ & $\begin{array}{c}\text { Canterbury Earthquake Recovery } \\
\text { Authority (CRA), Christchurch } \\
\text { City Council (CCC), Independent } \\
\text { Hearings Panels }\end{array}$ & $\begin{array}{c}\text { Likelihood of future adverse events, life safety, land } \\
\text { and property damage, economic loss, feasibility } \\
\text { (logistics, confidence, timeliness, cost cffectiveness) } \\
\text { of engineering solutions, timeliness of social and } \\
\text { infrastructural recovery }\end{array}$ & $\mathrm{Y}$ & $\begin{array}{l}\mathrm{Y}(\mathrm{S} 1 \mathrm{a}), \mathrm{N} \\
(\mathrm{S} 1 \mathrm{~b})\end{array}$ \\
\hline \begin{tabular}{|c|} 
Communicating uncertainty \\
to farmers at the forefront of \\
developing irrigated broad \\
acre agricultural farming \\
systems in Northern \\
Queensland (S2)
\end{tabular} & $\begin{array}{c}\text { University researchers, State } \\
\text { industry development } \\
\text { officers }\end{array}$ & Farmers/ Farmer advisors & $\begin{array}{c}\text { Climate variblity, uncetanty in model accuracy for the } \\
\text { given region }\end{array}$ & $\mathrm{Y}$ & $\mathrm{N}$ \\
\hline \begin{tabular}{|c|}
$\begin{array}{c}\text { Communicating uncertainty } \\
\text { in operational flood models } \\
\text { to decision makers: } \\
\text { challenges from the field }\end{array}$ \\
(S3) \\
\end{tabular} & \begin{tabular}{|c|} 
Flood forccasters and \\
analysts, Bureau of \\
Meteorology, data owners
\end{tabular} & $\begin{array}{l}\text { Local council, emergency } \\
\text { management agencies. }\end{array}$ & $\begin{array}{c}\text { Model accuracy and costs (run time, data } \\
\text { requirements). Likclihood of flood inundation, } \\
\text { duration of flood inundation or isolation, life safety. } \\
\text { Likelihood of a given response resulting from a } \\
\text { communication. }\end{array}$ & $\mathrm{Y}$ & $\mathrm{N}$ \\
\hline $\begin{array}{c}\text { Developing a state-wide } \\
\text { natural disaster risk } \\
\text { assessment for Tasmania, } \\
\text { Australia (S4) }\end{array}$ & \begin{tabular}{|c|} 
University researchers, State \\
Government agchncics and \\
departments, Bureau of \\
Meteorology, industry \\
specialists and experts
\end{tabular} & $\begin{array}{c}\text { State Government departments } \\
\text { and emergency management } \\
\text { agencies (including Department } \\
\text { of Premier and Cabinct, } \\
\text { Department of Primary Industries, } \\
\text { Parks, Water and Environment, } \\
\text { Department of State Growth, State } \\
\text { Emergency Service, Ambulance } \\
\text { Tasmaniaiand Tasmania Fire } \\
\text { Service, emergency response } \\
\text { agencies (including Red Cross), } \\
\text { and infrastructure owners and } \\
\text { utilities (including Tas Networks } \\
\text { and Hydro Tasmania) }\end{array}$ & \begin{tabular}{|c|} 
Tasmania's 'state level' priority emergency natural \\
disasters (including bushfire, flood, heatwave, coastal \\
inundation, storms, tsunami, carthquake, landslide, \\
and human influenza pandemic) across the \\
consequences categories of Pecople, Fonomic, \\
Environmental, Public Administration and Social \\
Setting (each with their own sub-categories)
\end{tabular} & $\mathrm{Y}$ & $\mathrm{Y}$ \\
\hline \begin{tabular}{|c|} 
Science contributions to \\
decision making related to \\
deep sea mining in New \\
Zealand's EEZ and \\
continental shelf (S5)
\end{tabular} & \begin{tabular}{|c|} 
Crown research institutes, \\
university researchers, \\
industry scientists and \\
consultants
\end{tabular} & $\begin{array}{c}\text { EPA Board appointed Decision- } \\
\text { making committee (DMC) of } \\
\text { qualified experts }\end{array}$ & \begin{tabular}{|c|} 
The likelihood of significant and permanent adverse \\
effects on the benthic enviroment, adverse effects on \\
trophic web, fish and other pelagic fauna, rock \\
lobsters, paua, water quality and seabirds; effects of \\
mining-related noise, including on marine mammals; \\
risks to biosecurity and human health
\end{tabular} & $\mathrm{Y}$ & $\mathrm{Y}$ \\
\hline \begin{tabular}{|c|} 
Locating and assessing \\
sources of uncertainty in 3D \\
geological models (S6) \\
\end{tabular} & $\begin{array}{l}\text { Industry scientists, } \\
\text { government agencies }\end{array}$ & Mineral and petroleum industry & $\begin{array}{l}\text { Model reliability. Likelihood of intersecting target } \\
\text { rock units during costly diilling and exploration } \\
\text { campaigns. }\end{array}$ & $\mathrm{Y}$ & $\mathrm{Y}$ \\
\hline $\begin{array}{l}\text { Loads estimation and } \\
\text { reporting in the Great } \\
\text { Barrier Reef: } \\
\text { communication and } \\
\text { challenges ( } \mathbf{S 7} \text { ) }\end{array}$ & $\begin{array}{l}\text { Government Agencies, } \\
\text { university researchers, } \\
\text { Industry scientists and } \\
\text { consultants }\end{array}$ & $\begin{array}{c}\text { Independent Expert Panel } \\
\text { (providing scientific and expert } \\
\text { advice relating to the GBR), Reef } \\
2050 \text { Advisory Committee } \\
\text { (providing strategic advice on } \\
\text { Reef } 2050 \text { actions) }\end{array}$ & \begin{tabular}{|c|} 
Relative risks to the Great Barrier Reef from degraded \\
water quality (e.g. nitrogen discharge and its \\
association of crown of thorns starfish resulting in \\
coral decline, fine sediment discharge reducing light \\
availability causing declinc in seagrass communitics, \\
pesticides providing a risk to freshwater and inshore \\
coastal habitats)
\end{tabular} & $\mathrm{Y}$ & $\mathrm{N}$ \\
\hline
\end{tabular}

Table 1 Case study science provider and decision-maker identities, risks considered, and inclusion of initially solicited vs. unsolicited science provisions in decision-making.

decision-making through inclusion of information from new science providers in response to stakeholder requests (S1, S5).

Table 2 summarizes the stimulating effects, consequences and decisionmaking needs for each case study. In S1, earthquake-triggered phenomena (stimulating effects) including rockfalls, cliff collapse, and liquefaction caused fatalities, injuries, and damage to land and infrastructure (consequences). The decision-making needs related to the responsibility of government agencies to address life safety, socioeconomic and infrastructure risks associated with these and future possible effects. When considering risk mitigation and avoidance strategies, prohibitive land re-zoning emerged as a justifiable decision pathway. In S2, agricultural development (stimulating effect), driven by maximising financial returns (consequences), led to decision-making needs for farmers in 


\begin{tabular}{|c|c|c|c|}
\hline Case study & Stimulating effects & Consequences & Decision-maker needs \\
\hline S1 & $\begin{array}{l}\text { Earthquake hazards (liquefaction, rockfall, } \\
\text { cliff collapse) }\end{array}$ & $\begin{array}{l}\text { Fatalities, injuries, land and property } \\
\text { damage }\end{array}$ & $\begin{array}{c}\text { Reduce risk of exposure } \\
\text { and loss from future } \\
\text { stimuli and associated } \\
\text { effects }\end{array}$ \\
\hline S2 & Agricultural development & $\begin{array}{l}\text { Adverse economic and environmental } \\
\text { impacts }\end{array}$ & $\begin{array}{l}\text { Reduced risk of poor } \\
\text { investment returns and } \\
\text { crop yield loss from } \\
\text { poor management }\end{array}$ \\
\hline S3 & Floods & Fatalites, injuries & $\begin{array}{c}\text { Reduce risk of exposure } \\
\text { and loss from future } \\
\text { stimuli and associated } \\
\text { effects }\end{array}$ \\
\hline S4 & $\begin{array}{l}\text { Bushfire, flood, heatwave, coastal } \\
\text { inundation, storms, tsunami, earthquake, } \\
\text { landslide, and human influenza pandemic }\end{array}$ & $\begin{array}{c}\text { Adverse health and socioeconomic } \\
\text { impacts on people, environments, public } \\
\text { administrations } \\
\end{array}$ & $\begin{array}{l}\text { Reduce risk through } \\
\text { prioritization and } \\
\text { effective treatment }\end{array}$ \\
\hline S5 & Mining in a deep-sea environment & $\begin{array}{l}\text { Adverse societal, economic and } \\
\text { environmental impacts }\end{array}$ & $\begin{array}{l}\text { Reduce uncertainty and } \\
\text { risk of adverse effects of } \\
\text { the activity on the } \\
\text { environment and } \\
\text { exisiting parites }\end{array}$ \\
\hline S6 & Resource development & Adverse economic impacts & $\begin{array}{l}\text { Reduce risks associated } \\
\text { with mineral discovery } \\
\text { and resource recovery }\end{array}$ \\
\hline S7 & Pollutant delivery to the Great Barrier Reef & Environmental pollution & $\begin{array}{c}\text { Reduce risks of } \\
\text { pollution delivery to the } \\
\text { Great Barrier Reef }\end{array}$ \\
\hline
\end{tabular}

Table 2 Stimulating effects, consequences and decision-making needs for each case study.

choosing crops and inputs. In S3, flooding events in urban areas (stimulating effects) were studied using forecast models to examine the potential for isolation or inundation of properties (consequences). The potential occurrence of fatalities, injuries and loss of services defines a need for emergency managers to understand and respond to these risks. In S4, the combined threat of bushfires, tsunamis, influenza pandemics and other natural disasters (stimulating effects) on the population and environment (consequences), resulted in decision-making needs for the Tasmanian emergency management sector regarding prioritization of risk-reduction actions. In S5, prospective deep-sea mining in New Zealand's Exclusive Economic Zone (stimulating effect) and its impact on the benthic environment (consequences), required the decisionmaking authority to balance the financial incentives versus the potential environmental damage. In S6, oil and gas exploration (stimulating effect) is a costly and hazardous undertaking with lucrative financial rewards (consequences), resulting in decision-makers needing reliable predictions of the location and value of the natural resources to maximize productivity and profits. In S7, declining water quality due to land based pollutant discharge (stimulating effects) has adversely impacted coral and seagrass communities, reducing the 


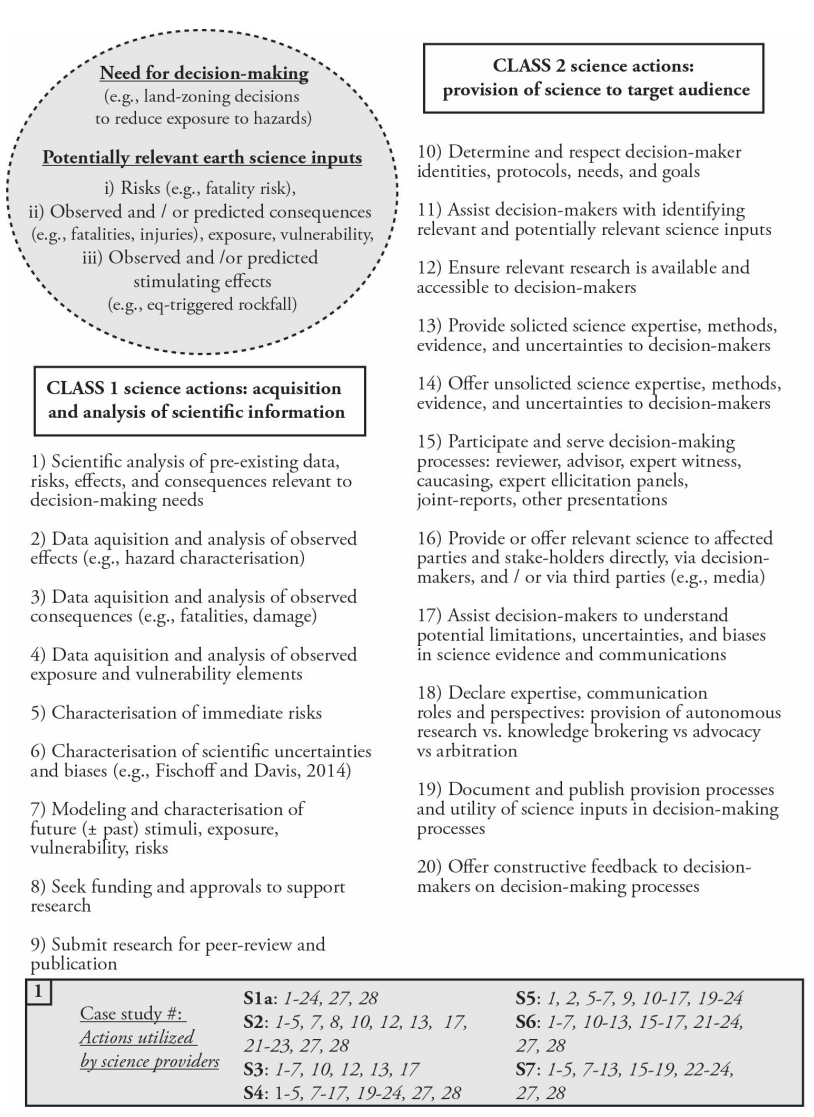

\begin{tabular}{|c|c|}
\hline & $\begin{array}{l}\text { CLASS } 3 \text { scientific actions: } \\
\text { enhancing future provision and } \\
\text { tilitity of science to decision-makers }\end{array}$ \\
\hline \multicolumn{2}{|c|}{$\begin{array}{l}\text { 21) Offer further scientific expertise, } \\
\text { methods, evidence, and uncertainties to } \\
\text { decision-makers to assist in identifying } \\
\text { future decision-making needs, risks, and } \\
\text { potentially relevant science inputs }\end{array}$} \\
\hline \multicolumn{2}{|c|}{$\begin{array}{l}\text { 22) Continue to conduct scientific research } \\
\text { relevant to past and future decision-making } \\
\text { needs }\end{array}$} \\
\hline \multicolumn{2}{|c|}{$\begin{array}{l}\text { 23) Maintain existing and build new } \\
\text { relationships with decision-makers and } \\
\text { associated bodies }\end{array}$} \\
\hline \multicolumn{2}{|c|}{$\begin{array}{l}\text { 24) Communicate research relevant to past } \\
\text { and future decisions to decision-makers, } \\
\text { stake-holders, and the general public }\end{array}$} \\
\hline \multicolumn{2}{|c|}{$\begin{array}{l}\text { 25) Test and offer feedback to improve } \\
\text { existing science provisionary pathways }\end{array}$} \\
\hline \multicolumn{2}{|c|}{$\begin{array}{l}\text { 26) Propose and assist in construction of } \\
\text { new science provisionary pathways }\end{array}$} \\
\hline \multicolumn{2}{|c|}{$\begin{array}{l}\text { 27) Maintain awareness of relevant science } \\
\text { and science providers }\end{array}$} \\
\hline \multicolumn{2}{|c|}{$\begin{array}{l}\text { 28) Maintain availability and accessibility o } \\
\text { relevant science and scientific expertise }\end{array}$} \\
\hline & $\begin{array}{l}\text { Case study \#: Examples of viable } \\
\text { science provision pathways }\end{array}$ \\
\hline & $\begin{array}{l}\text { S1a: } 2-3-4-8-1-7-6-5-9-12-16-14-10- \\
\text { 13-15-18-17-11-20-21-22-24-27-28 } \\
\text { S2: } 10-1-2-3-4-5-7-12-13-17-21-8- \\
\text { 22-23-27-28 } \\
\text { S3: } 2-4-5-6-13-17 \\
\text { S4: } 1-2-3-4-5-11-12-17-21-24 \\
\text { S5: } 1-2-5-6-7-9-10-11-12-16-13-15- \\
17-19-20-21-22-23-24 \\
\text { 66: } 10-1-6-7-19-13-21 \\
\text { 57: } 10-1-2-3-4-7-6-5-9-12-13- \\
15-17-20-21-24-27-28\end{array}$ \\
\hline
\end{tabular}

Fig. 1 Science provider actions and provision pathways.

habitat for marine life (consequences), and decision-maker needs are driven by reducing these impacts.

Not all decision-making needs are explicitly motivated by reducing adverse risks, but all are affected by adverse risks. For example, decision-maker needs in S2 and S6 are motivated by increasing agricultural and geological resource productivity, respectively, but both contain adverse risks such as environmental damage and increased fiscal expenditure without sufficient productivity that results in net economic loss.

\subsection{Science actions and provision pathways}

Figure 1 shows how scientists may meet the needs of decision-makers by acquiring, analysing and communicating scientific information using a variety of science actions. It presents one possible schema to classify and order science actions. This schema was developed based on the common experiences and insights of the authors. The categorization and organization of actions 
is consistent with prior work. While not exhaustive, the schema provides an organisation of steps for consideration by scientists when communicating uncertainty to decision-makers. Not all steps are warranted, or practicable, in all situations. However, consideration of all steps is warranted as it may prompt identification of actions that would improve communication under uncertainty. In Figure 1. science actions are Class 1 - acquisition and analysis of scientific information; Class 2 - provision of science to target audience; Class 3 - enhancing future provision and utility of science to decision-makers. Inherent in these actions is adherence to ethical scientific conduct (Science Council of Japan, 2013: Doyle et al., 2019).

The scientific actions described in Figure 1 may be concurrently or sequentially undertaken by multiple science providers comprising multiple individuals and/or collectives. Box 1 of Figure 1 lists the scientific actions undertaken in the seven case studies by at least one science provider (and known to the authors of this paper).

Box 2 of Figure 1 provides viable science provision pathways that reveal the order in which a suite of actions undertaken by a specific individual or group led to ultimate acquisition and utility of scientific information by decisionmakers. By "viable", we simply mean that the actions are listed in a generalized chronologic order, although many actions may have been undertaken concurrently with others. This model framework significantly simplifies the full complexity and populous of possible science actions and provision pathways. Its purpose, however, is to offer examples of some of the diverse actions and pathways by which science providers have communicated to decision-makers throughout the decision-making process, as discussed below.

In S1a, scientists used almost all listed actions and science provision pathways. In response to fatalities and land and property damage caused by rockfall in the Christchurch earthquakes, the Christchurch City Council (CCC), with additional funding from the NZ Natural Hazard Research Platform (NZHRP), commissioned investigations by the government research institute GNS Science and university and industry partners to quantify and construct maps of the annual individual fatality risk (AIFR) posed by future rockfall in residential areas (Massey et al., 2014). AIFR maps were used by CCC to define residential red zones, where life safety risk from future rockfalls was deemed to be beyond societally tolerable. In this instance, $\mathrm{CCC}$ was the decision-maker. Affected parties (e.g., landowners) were given the opportunity to challenge red zone decisions in independent submissions to a hearings board; in this instance the hearing board panelists were the decision-makers. GNS Scientists and collaborators communicated ongoing research and results to decision-makers, stake-holders, immediately affected members of the public, and the public-at-large. Prior to and concurrent with this process, an independent group of university-based scientists conducted and published research on pre-historic rockfalls and their implications for contemporary hazards. This research was ultimately provided to and considered by decision-makers in the hearings, although the researchers did not initially undertake the research for this purpose. The order of actions conducted by these researchers initiated with acquisition and analysis of rock- 
fall effects (\#2), consequences (\#3) vulnerabilities and exposure (\#4) that enabled the formulation of research questions and methods that were used to seek research funding and approval for further site studies (\#8). Subsequent research $(\# 1, \# 7, \# 6, \# 5)$ was submitted for peer review, published (Mackey and Quigley, 2014), and made publicly available through the author's (MQ's) personal website $(\# 12)$. The authors notified the media of their results, and an article on their research findings was published in the Christchurch Press 4 Some affected landowners read this article, considered the implications of results, and invited an author of the research (MQ) to submit the article as evidence to the hearings (\#14). MQ noted the identities and protocols of the decision-makers (\#10) and submitted additional supporting evidence in response to solicitation by the decision-making panel (\#13). He participated in group caucusing, joint statement authoring, and was interviewed as an expert witness (\#15) where explicit statements pertaining the role, expertise, and perspectives of the author (\#18), the limitations, uncertainties, and potential biases of the contributed science evidence (\#17), additional relevant inputs (\#11), and constructive comments pertaining to the decision-making process (\#20) were made publicly available 5 Class 3 actions (\#21, \#22, \#24, $\# 27, \# 28$ ) were also undertaken following completion of the decision-making process (Figure 1).

S2 describes interactions between decision-makers and science providers initiated by a query from a farming industry member (a decision-maker) to a scientific researcher. The scientist first defined the decision-maker's goals (\#10), then acquired and analyzed relevant scientific data $(\# 1-5, \# 7)$. The provision of scientific information to the decision-maker in this case had a narrow scope $(\# 12, \# 13, \# 17)$, reflecting the specificity of the enquiry. Noting the potential broader industry impact, the scientist sought additional funding and resources (\#8) to expand the research and subsequent dissemination (\#22, \#23, \#27, \#28).

In S3, many of the science actions and pathways used are constrained by the restricted time frames inherent in an operational response to flooding (or any natural disaster). Routine flood forecasting activities (non-operational) ensure flood forecasters are familiar with the science of pre-existing data, risks, effects and expected consequences (\#1). Flood forecasts are undertaken using weather forecasts and observational data $(\# 2, \# 6)$, and with consideration of the needs of the decision makers (\#10). The forecasts are provided to decisionmakers (\#13), who may solicit scientific advice on impacts (\#3-5) from other parties or determine those potential impacts directly.

S4 includes an extensive suite of science actions undertaken by author CW and the contributing science providers of the Tasmanian State Natural Disaster Risk Assessment (White et al. 2016). Led by science providers, the assessment provided an opportunity for a diverse range of expert voices and

4 http://www.stuff.co.nz/national/10574099/Alpine-Fault-unlikely-to-trigger-Port-Hillsrockfall

5 http://www.chchplan.ihp.govt.nz/wp-content/uploads/2015/03/Natural-HazardsPart.pdf 
decision-makers to come together in a risk-based workshop setting to identify (\#1-5, \#7) and collaboratively assess (\#12-17) Tasmania's "state level" priority emergency risks, noting that Tasmania was the first Australian state or territory to undertake this national mandate. The examples of the science provision pathways (\#21-24) may be useful for science providers undertaking this process elsewhere.

In S5, science actions and provision pathways were built into a mining company's consent application. Class 1 actions underpinned the early stages of the application process, in which the consent applicant was required to demonstrate understanding of the current state of the environment, the potential environmental issues and prepare impact assessments for these issues $(\# 1, \# 2, \# 57, \# 9)$. Class 2 actions began once the application was received, at which time third party scientific advice was sought by the decision-makers, and the application underwent six lodgment reviews for more complete scientific information (\#10-13, \#15-20). In total, 75 submitters made 294 submissions with requests to appear at the hearing (\#14). In refusing the application, the decision-maker effectively nullified possible Class 3 actions (e.g., \#21-24) within the confines of the case.

In S6, the utility of Class 1 science actions and Class 2 science provision actions pertain primarily to fiscal interests of mining and petroleum companies seeking to maximize their ability to explore for and extract an economic resource. Any given science provider may be directed in specific manner (i.e., using a small selection of total actions used by all science providers) to provide highly specialized information relevant to the targeted objectives of the company at the given time. These objectives are typically related to whether a resource is to be developed, held, or abandoned, which are decisions that each have different levels of risk. Developing a resource requires significant investment in order to achieve financially viable production. Holding a resource is usually done in order to plan development at a later stage, either for market reasons, such as a forecast increase in commodity prices or decrease in labour costs, or in anticipation of a joint venture agreement or share market offering that attracts investment and finances development. Abandoning is to either decommission or sell the resource. While these decisions have been listed in order of decreasing cost, other factors, such as market sentiment and geopolitics, may change this ranking. Nonetheless, geological uncertainty is central to these decisions which often determine the fate of a company. This is reflected in the example viable pathway, in which action \#10 is the first to be undertaken. Uncertainty characterisation and data modelling actions comprise early steps in the sequence, and only a select group of the listed actions are delineated.

In S7, scientific actions in GBR decision-making have focused heavily on Class 1 (\#1-5, \#7-9), with scientists able to conduct scientific analysis of the status and trends of the reef through Australian Government funding initiatives aimed at addressing issues outlined in the Reef Plan ${ }^{6}$ Class 2 actions

6 http://www.environment.gov.au/marine/gbr/long-term-sustainability-plan 


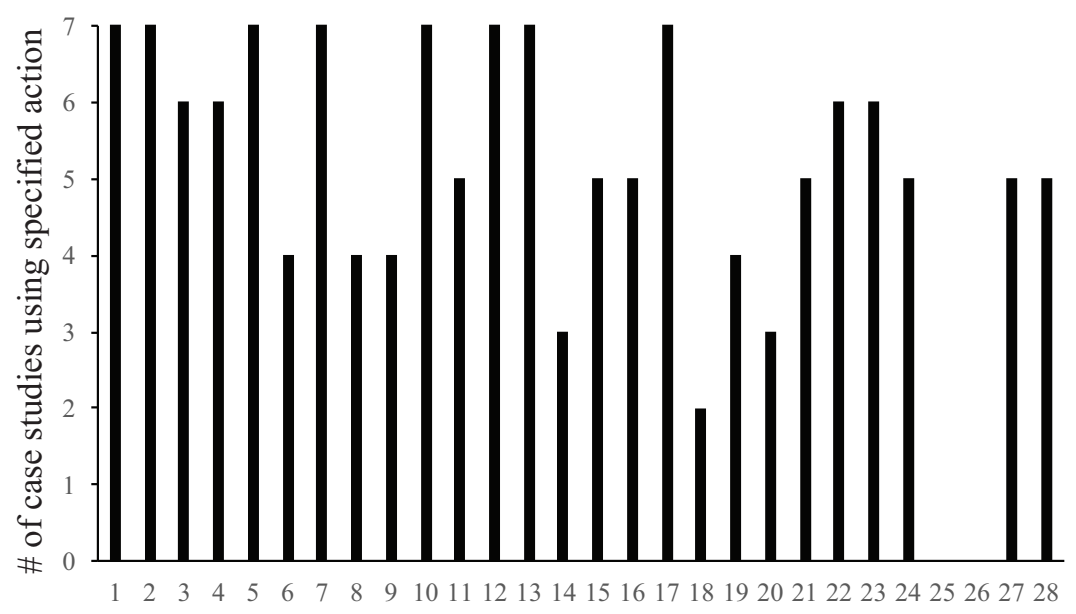

Action \#

Fig. 2 Summary of science actions utilized in the case studies. (See Figure 1 for corresponding description of Action \#.)

(\#10-13, \#15-19) have received less focus, and Class 3 actions (\#22-24, \#2728) have been limited, although this is improving as evidenced through formation of GBR stakeholder groups and recent government funding targeting reef restoration activities.

Figure 2 summarizes the usage of science actions across the case studies. Actions \#6, \#11, \#18, \#19, \#20 and \#25-26 are identified as under-utilized actions in the cases considered, and, therefore, potentially in the broader realm of decision-making. These actions may be considered avenues for improvement within the scientific community, although the context of these actions is important. For example, not all actions and pathways in Figures 1 and 2 may be viable for all scenarios. Some under-utilized actions (\#8-9, \#14-15, \#16) are likely to be highly scenario-specific, with their utility conditional upon provider and decision-maker identities, needs, and internal and external protocols and influences. In some scenarios, undertaking actions not listed here, or within a different context, or in different order from those evidenced here could have adverse effects. Science provisions directly to affected parties or stake-holders through the media (\#16) could generate potentially harmful effects in emergency-related situations (S3) or industry-funded activities (S6). Similarly, undertaking this action prior to peer-review (\#9) might not be appropriate if the underlying science has not been independently evaluated or supported by accessible evidence. As evidenced by S1a, undertaking action (\#16) within a robust provision pathway offers a strategic option for science providers seeking to advocate for unsolicited but relevant science in decision-making. Actions \#25-26, which pertain to improving science provision pathways, were not utilized in any of the case studies. Nevertheless, they 
were identified by the authors as desirable actions based on their experiences. Consideration of how pathways for the communication of scientific advice can be improved is always warranted, even if improvements cannot be identified and/or implemented.

\subsection{Scientific inputs to decision-making: Decision trees}

Figure 3 provides decision trees that reveal how scientific inputs entered decision-making frameworks. The overarching question for which decision-making is required (bold and underlined questions) is underpinned by a sequence of incremental questions (boxes) that are described in more detail and placed into context (italics) with a sample representative decision-making pathways indicated (circled options).

Figures $3 \mathrm{a}-\mathrm{b}$ show pathways from S1a. These represent empirically-evidenced decision-making scenarios where the decision trees present sample decision pathways enacted for a specific individual property at risk from rockfall and/or cliff collapse. Red-zone decisions were considered as an avoidance strategy to reduce risks to life and infrastructure from future rockfall (Figure 3a) and cliff collapse (Figure 3b). Figures 3c-d show liquefaction decision trees deduced from CERA-issued initial public documents explaining the justification for liquefaction red-zone decisions (Figure 3c), and deduced from an initially confidential Cabinet memorandum presented to the government by the Minister for Earthquake Recovery (Figure 3d). The primary distinction among these decision trees is, on the surface, the explicit inclusion of science and engineering criteria in the public document (Figure 3c) versus the strictly economic parameters discussed by Cabinet (Figure 3d); further analysis of this aspect is the focus of ongoing research. The enacted red-zone decisions shown in Figures 3a-d comprise only a small percentage of the total decisions in the region that resulted in approval for ongoing residential consent (green-zone; $\approx 200,000$ buildings).

Figures $3 e, f, h$ provide decision trees for scenarios where different pathways arise as farmers (S2), emergency managers (S3) or resource companies (S6) may encounter different values of scientific and non-scientific inputs at each of the incremental steps. Figure $3 \mathrm{~g}$ shows a specific, empirically-evidenced decision-making scenario from S5 in which the delineated pathway was taken by decision-makers to decline a mining consent. Figure 3i provides a theoretical example of a decision-making framework that could be (but has not been) implemented for a specifically-defined scenario (S7).

The order of sub-questions in the decision trees is not intended to represent the decision-making process as linear and sequential. In some cases, decisionmakers addressed many sub-questions concurrently or in a different order from that specified in Figure 3. Two examples of the non-linearity of decision trees exist in S2. Firstly, sensible testing of the modelling of proposed crop management change (Figure 3e, 4th box) could highlight the need for a reassessment of the effectiveness of the crop growth models themselves (Figure 3e, 3rd box). 


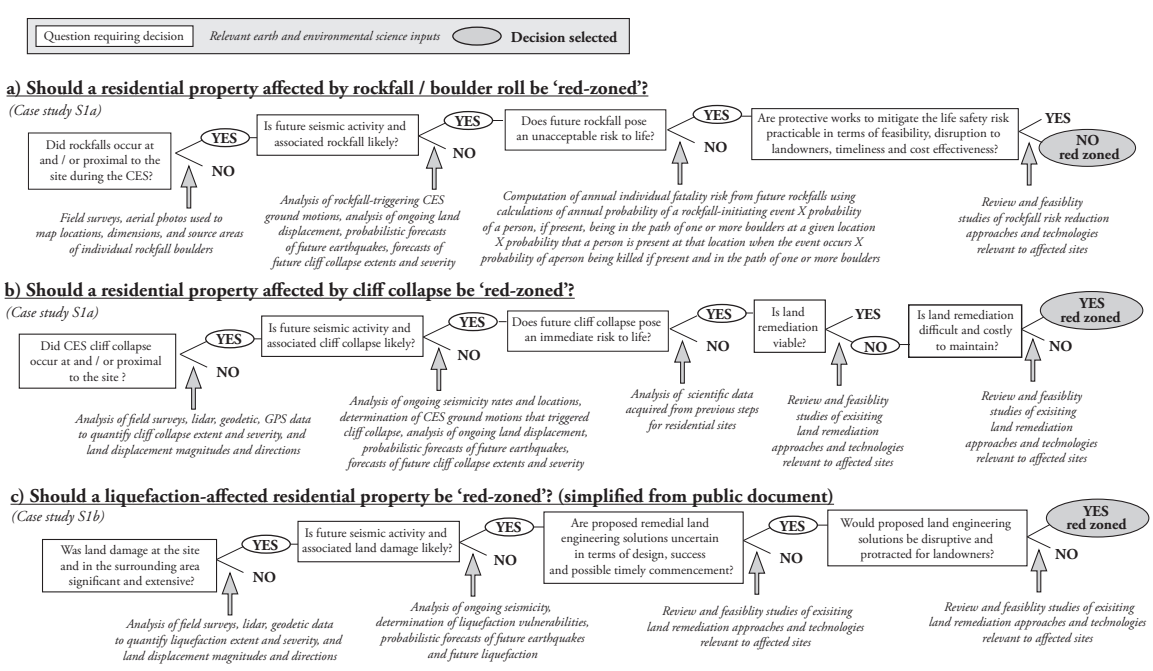

d) Should a liquefaction-affected residential property be 'red-zoned'? (economic criteria presented to Cabinet by Minister for earthquake recovery) (Cases study SIb)

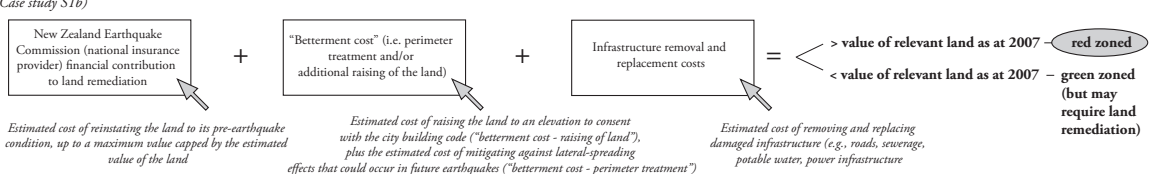

e) Should a farmer change agricultural practice to increase the likelihood of maximum crop yields in a new agricultural region?


Fig. 3 Decision trees. Questions requiring decision-making appear in bold underline with affiliated case study number listed in italics beneath. Boxes denote sub-questions related to the overarching question. Italics provide details on the nature and context of science provisions relevant to each sub-question. Sample pathways indicated with circles and final decision denoted by grey-coloured circle.

Second, if the proposed management change is not possible due to fiscal or economic constraints (Figure 3e, 5th and 6th boxes), other potential changes may be investigated (Figure 3, 4th box). Some decision trees are also simplified interpretations of highly complex decision-making pathways. For example, in S5 (Figure 3g) the decision-making committee appointed to rule on the deepsea mining application made 44 additional requests for further information 
Figure 3 (g-i): Examples of decision trees and relevant earth and environmental scientific inputs for decisions considered in this study

g) Should consent for deep sea phosphate mining in New Zealand's exclusive economic zone (EEZ) be granted?

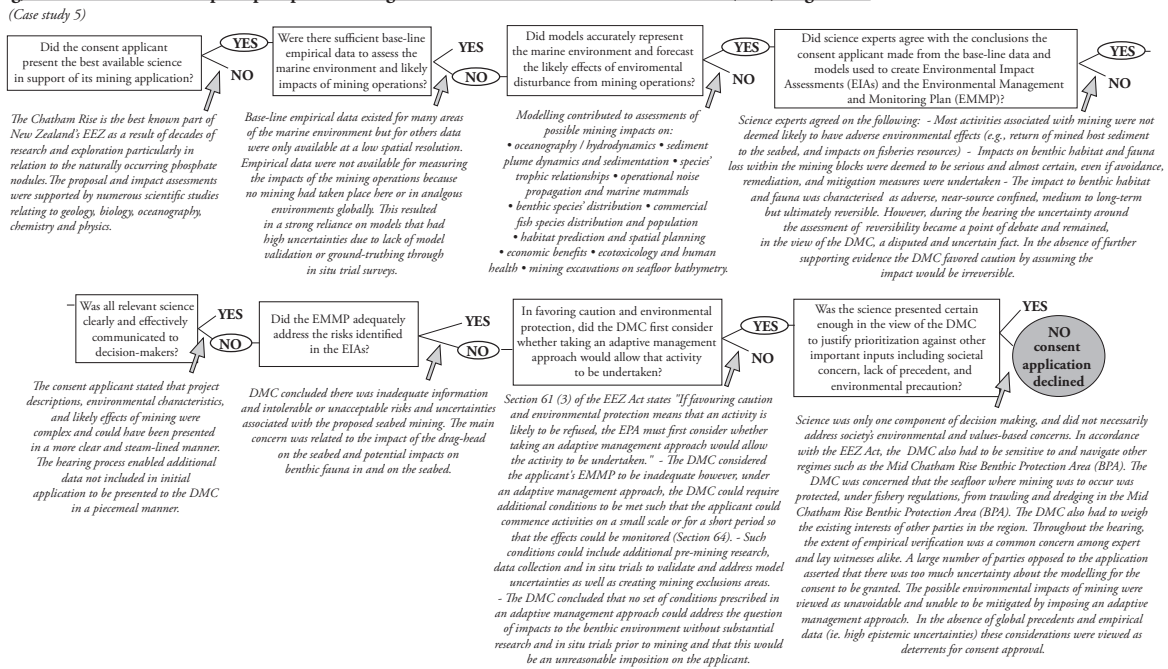

h) Should resource exploration and extraction strategies, volume estimates, and value assessments utilize this $3 \mathrm{D}$ model? (Cases study 6

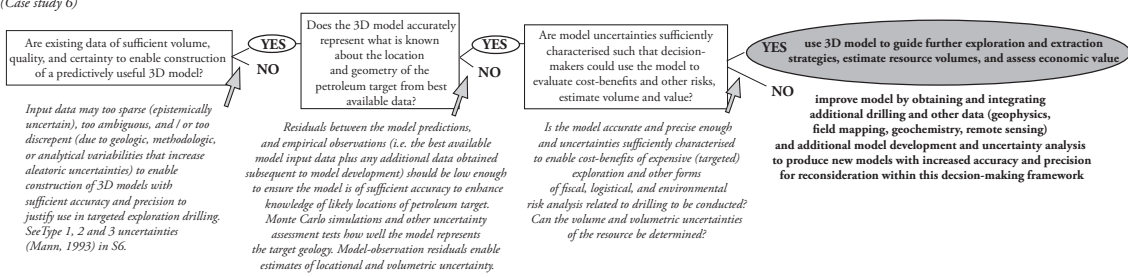

i) Should catchment management practices change to reduce pollutant delivery to the Great Barrier Reef?

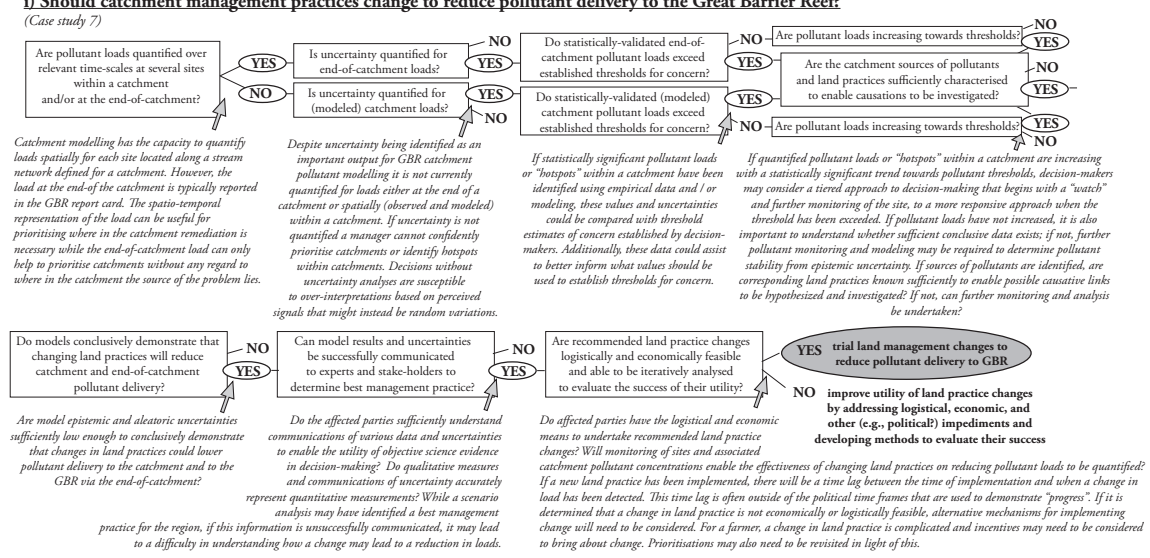

Fig. 3 continued 
from the applicant on many topics, even after the application was accepted as complete by the Environmental Protection Authority of New Zealand. The rockfall (S1a) and liquefaction (S1b) cases offer an interesting contrast; in the case of S1a, a large volume of detailed scientific information was acquired prior to decision-making, to the detriment of decision-making expediency, while in S1b, science inputs are not present as specified entities, almost certainly (in part) because of the acknowledged need for decision-makers to expedite the provision of certainty to affected landowners. It is likely that defining the individual life safety risks in S1a were prioritized above expediency, while the risks in S1b were largely socioeconomic in nature and could be more rapidly assessed using the expert opinions of scientists and engineers, rather than extensive acquisition of additional scientific information.

In addition to science inputs, decision-makers identified engineering (Figures $3 \mathrm{a}-\mathrm{c}, \mathrm{e}, \mathrm{g}$ ), economic (Figures $3 \mathrm{a}, \mathrm{b}, \mathrm{e}, \mathrm{g}-\mathrm{i}$ ), and societal inputs including life safety and well-being (Figure $3 \mathrm{a}^{-} \mathrm{c}, \mathrm{f}, \mathrm{g}$ ) as relevant inputs. Some of these inputs are co-dependent upon earth science inputs. For example, the economic viability of a potential engineering solution (e.g., rockfall protection in S1) and its ability to reduce life safety risk relates to hazard (i.e., frequency-distributionseverity of rockfall), exposure (i.e., will rockfall boulders travel into populated areas), and vulnerability elements (i.e., are boulder impact energies likely to exceed resisting strengths of existing infrastructure?) that depend in part upon earth science inputs for quantification. Some decisions are likely to have been influenced by additional inputs that are less dependent on earth science evidence, including (i) insurance (King et al., 2014), which might have better equipped decision-makers to undertake decision-making with large economic losses, (ii) stake-holder opinion, such as prevailing public opinion in policybased decisions that was (S1, Figures 3a-c) or was not (S5, Figure 3g) wellaligned with prevailing science evidence, (iii) company share-holder priority economic interests in industry-related decisions (S6, Figure 3h), and (iv) political motivations and risks (S7, Figure 3i). Intriguingly, some enacted decisions $(\mathrm{S} 1, \mathrm{~S} 5)$ were selected despite the availability of more economically-favourable decision alternatives. In S1, community life safety and socioeconomic risks were prioritized despite a large financial cost to the central government, and in S5 a precautionary approach to environmental risks was prioritized above the potential for economic benefits from mining.

The decision trees presented in Figure 3a,b,c,g may all be considered examples of scientifically-informed (i.e., a diverse range of relevant science inputs were considered), precautionary decisions (i.e., the risks associated with large epistemic and statistical uncertainties in some of the science inputs were considered in a risk-adverse manner) with adaptive capacity (i.e., property owners in S1 and the mining company in S5 were given opportunities to appeal initial decisions). In S1, independent reviews and hearings resulted in new decisions (e.g., some red-zone properties were green-zoned and vice versa).

A common element among the decision trees is the progression from an initial phase, where preliminary decision-making steps are informed by scientific observations, data, analyses, and expert judgment, to an intermediate phase 
informed by science-based simulations and forecast models of future scenarios, to a later phase, including risk-based feasibility and cost-benefit analyses of future scenarios, during which other (non-earth science) inputs may be most relevant in influencing decision-making pathways. This highlights an important aspect of science-informed decision-making; earth science may play an important role in shaping the initial trajectory of decision-making in response to a specific risk, however, other inputs (e.g., economic, feasibility, political) may ultimately be more influential in decision-making, particularly at crucial late-stage increments. Science providers should be aware of this aspect and may wish to continue to undertake science actions including advocacy (Figure 1) during the later stages of decision-making to promote continued science utility in the latter stages of decision-making. The use of independent (nonpolitical) decision-making bodies (S1, S3, S5) where appropriate appears to reduce the potential of political inputs to transcend science inputs in late-stage decision-making. In contrast, involvement of government agencies in science assessments might improve the potential for uptake of the scientific information and integration into policy (S4).

\subsection{Assessing science utility in decision-making}

In Figure 4, we perform a self-assessment for each case study using an elicitation approach promoted by Speirs-Bridge et al. (2010) as a method for reducing overconfidence in the interval judgments of experts. The authors were invited to respond about scientific uptake and agreement with respect to their individual case study using a 4-point elicitation procedure that asks for a lower limit, upper limit, best guess and a level of confidence in the interval that they provided. The following questions were posed to authors of each case study:

\section{- Scientific Uptake}

1. In thinking about the potentially-relevant and available science (both data and expertise) used in decision-making, what do you think the lowest \% of uptake was for your case study?

2. In thinking about the potentially-relevant and available science (both data and expertise) used in decision-making, what do you think the highest $\%$ of uptake was for your case study?

3. In thinking about the potentially-relevant and available science (both data and expertise) used in decision-making, what is your best guess of the $\%$ uptake for your case study?

4. How confident are you that your interval, from lowest to highest, captures the scientific uptake for your case study?

- Scientific Agreement

1. In thinking about the scientific agreement amongst earth science inputs considered by decision-makers, what do you think the lowest $\%$ of agreement was for your case study? 


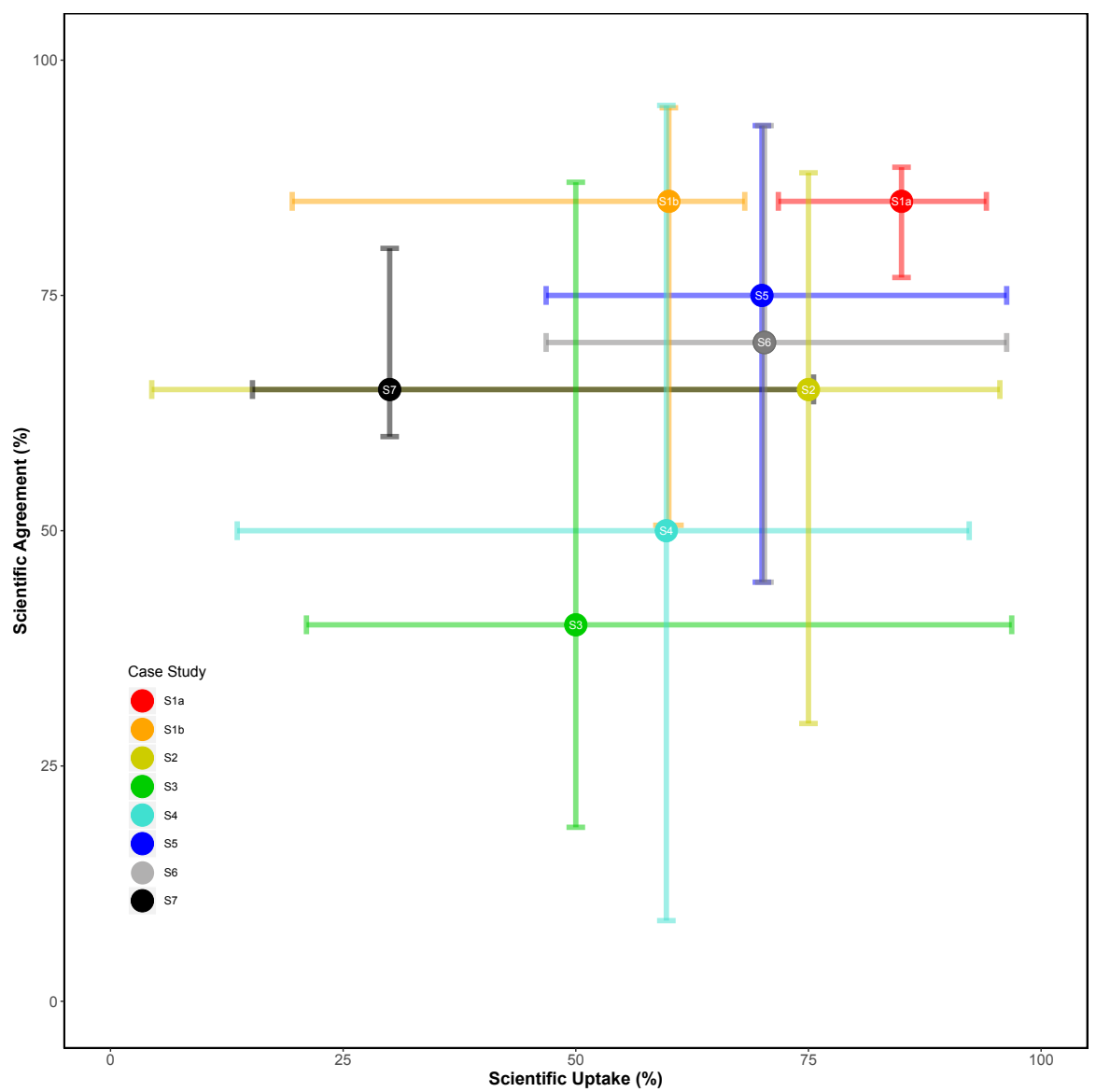

Fig. 4 Summary of science utility in decision-making. Elicited $80 \%$ confidence intervals showing each study's self-assessment in terms of scientific uptake as a percentage (x-axis) and scientific agreement as a percentage (y-axis). Elicited information for scientific agreement in the format (study \#, lower, upper, "best guess" and confidence) are (S1a, 75, 90, 85, 90), (S1b, 60, 90, 85, 60), (S2, 40, 80, 65, 60), (S3, 15, 90, 40, 85), (S4, 15, 90, 50, 70), (S5, 50, $90,75,70),(\mathrm{S} 6,50,90,70,70)$, and $(\mathrm{S} 7,60,80,65,80)$. Elicited information for scientific uptake in the format (study \#, lower, upper, "best guess" and confidence) are (S1a, 70, 95, 85, 85), (S1b, 10, 80, 60, 95), (S2, 10, 90, 75, 70), (S3, 82, 95, 50, 75), (S4, 10, 95, 60, 85), $(\mathrm{S} 5,50,95,70,75),(\mathrm{S} 6,50,95,70,75)$, and $(\mathrm{S} 7,20,70,30,70)$.

2. In thinking about the scientific agreement amongst earth science inputs considered by decision-makers, what do you think the highest $\%$ of agreement was for your case study?

3. In thinking about the scientific agreement amongst earth science inputs considered by decision-makers, what is your best guess of the \% agreement for your case study?

4. How confident are you that your interval, from lowest to highest, captures the percentage of scientific agreement for your case study? 
Estimates from the elicitation exercise are displayed as percentages (colored circles) in Figure 4 accompanied by $80 \%$ confidence intervals. These were constructed by assuming a normal distribution of arcsine values based on the level of confidence provided by each expert using the method proposed by Speirs-Bridge et al. (2010). In some instances, confidence intervals overlapped and therefore show a blending of colours corresponding to the respective case studies.

The majority of case studies reside in the top right quadrant of Figure 4, with the exception to S3 (floods) and S7 (pollutants to the GBR). This suggests that for the many of the case studies there is considerable scientific agreement and uptake of the methods, which is positive to note. While case study S2 (agriculture) and S1b (liquefaction) have their estimates (coloured circles) within this quadrant, there is a reasonable amount of uncertainty surrounding their respective estimate. In S1b, limited scientific information was available at the time of decision-making, but scientific and engineering experts were available to provide expert judgment to accommodate the needs of decision-makers to make expedient decisions. The scientific evidence obtained following decision-making ultimately supported the decisions made (Figure 3 $\mathrm{c}, \mathrm{d})$. This case provides an important example of how the expediency required for decision-making may not always enable relevant science to be obtained for potential utility. The lack of confidence with which we can estimate how science actually informed the (i) need for a land use policy, and (ii) the actual property-by-property decisions in S1b results in large uncertainties for this data point (Figure 4).

For S2, the interval elicited for scientific uptake is quite broad, revealing a lower bound of approximately $19 \%$ and an upper bound of $68 \%$. There is also large variability in the consideration and agreement of scientific data for this case study. For case studies like this that involve many different decisionmakers (e.g., individual farmers in S2, and different resource companies in S6) the error bars also reflect the potential variance in scientific consensus and utility amongst the specific decision-making cases (e.g., individual farms) that collectively comprise the case study. For example, scientific consensus might be high for one farm and low for another (thus defining a large error bar about a medium consensus centroid) and one farmer might use a large volume of science in decision-making while another might use very little (thus defining a medium utility value with large error bar).

Case study S3 (floods) resides close to the lower left quadrant of Figure 4, with reasonably wide confidence intervals, suggesting uncertainty in the uptake and agreement of scientific information. This a reflection of the the case study's focus on challenges in the communication of the uncertainty associated with scientific advice within the context of highly uncertain, and often variable throughout an event, flood and flood impact forecasting. Thus, while consideration of scientific advice is estimated (by the author) to be very high, uptake is estimated to be considerably more variable. This variability results from taking a precautionary approach with uncommunicated uncertainty and high time-pressures. For the case of pollutants to the GBR (case study S7), the 
estimate for the intersection between scientific agreement and uptake resides in the upper left quadrant of Figure 4. While scientific agreement may be confidently elicited to be high, there is considerable variability in terms of uptake and its best guess is elicited to be quite low, suggesting that there may be other factors preventing uptake outside the control of the scientific provider. It is interesting to note that both S5 (seabed mining) and S6 (resource modelling) convey similar information when considering scientific agreement and uptake, apart from the difference in the elicited best guess. This suggests the authors experiences with regards to these two case studies were similar and could be attributed to the nature of the decisions being sought.

It is difficult to imagine many case studies with estimates of uptake and agreement falling into the bottom right quadrant of Figure 4 as this would indicate scientific uptake when agreement was minimal. It would be more plausible when there is lack of scientific agreement to see little to no uptake on approaches.

Decisions may be less well aligned with prevailing contributing science if a lower proportion of available science was used and/or if there is less scientific consensus in the contributing science. For example, a high volume of scientific information (virtually all the relevant and available science that we are aware of, including published and unpublished data) was used by decisionmakers in S1a (rockfall risk land zoning). This was because (i) government officials tasked with immediately assessing societal risk funded specific scientific investigations to quantify these risks, (ii) decision-makers welcomed the submission of initially unsolicited science, (iii) decision-makers created independent review processes and welcomed additional evidence submissions from science providers during these processes including site-specific data, and (iv) decision-makers asked specific questions pertaining to the availability of scientific information during the decision-making process. There was also high consensus (as evidenced by joint-statements submitted by science providers) on most of the science evidence. When we consider uptake however, the confidence interval elicited is broader (71-94\%). The ultimate decisions varied from property to property, although science played an essential role in decisionmaking, and all decisions aligned with the best available science and/or provided opportunities for decision revisions if additional scientific information was presented. In S4 (disaster risks), scientific expertise was elucidated from a broad field (characterising risks from a diverse array of natural hazards), and was therefore highly variable (e.g., significant expertise existed in some specializations, but not in others). As a result, consensus on some contributing evidence (e.g., state-level consequence of a damaging earthquake in Tasmania) was medium-low, whereas for others (e.g., bushfire risk) it was far higher. Ultimately, the enacted decisions in S4 (i.e., the relative risk ranking of natural hazards) aligned with the majority of the available scientific evidence, however the involvement of additional experts might have reduced uncertainty in some aspects of the analysis. 


\section{Discussion}

Science can provide objective information relevant for decision-making, irrespective of the identities, research methods, and research motives (e.g., pure versus applied research) of the contributor(s). In many types of decisionmaking, it may be useful to consider multiple (and potentially conflicting) scientific inputs, and it is rare (often unfeasible) for decision-makers to be aware of all potentially relevant science (and scientists) that may be useful in addressing their needs. Rather than placing sole responsibility on decisionmakers to solicit relevant science, scientists may attempt to provide potentially relevant expertise and evidence without initial solicitation. Actions and pathways should be explored with the freedom of scientific endeavour but with an operative awareness of how science might contribute to the "bigger picture". Effective path-finding between science actions and provision to decision-makers usually requires time and effort to determine the identities, protocols, and needs of decision-makers, other relevant science providers, and stake-holders. Science provisions may be solicited or unsolicited, duly acknowledged or unrequited, formally or informally presented, and direct or highly indirect (e.g., traveling from research papers to media to stake-holders to decision-makers). These attributes require science providers to be strategic, adaptive, creative, and persistent. The possession of social and political intelligence may assist scientists to provide their expertise in the most appropriate manner and context to increase its utility, particularly where prevailing science evidence favours a decision that is opposed by other inputs. Decision-makers also have a responsibility to seek experts in a manner that scientists might find intuitive but which is rarely used, for example, by undertaking internet searches for relevant research publications, and/or providing potential pathways for the provision of unsolicited science. Four of the case studies considered showed use of these pathways and consideration of initially unsolicited science evidence in deliberations of decision-makers (Table 1). Importantly, there is no guarantee that increasing the provision of science will increase the quantity or quality of science used in decision-making. Ultimately, scientists must bear the responsibility for ensuring that the best and most relevant science is provided, whether it is their own or that of others.

There are many factors that limit the ability of scientists to provide their research evidence to decision-makers. Some of the factors are internal, for example, intra-institutional decisions on science communication strategies, selection of individuals for communications (such as hierarchical or talent-based communication frameworks), a perceived need for constant and consistent scientific messaging, and formal or informal institutional priorities and mandates, such as a legal obligation for a government-funded science agency to deliver relevant decision-making inputs through defined channels or to avoid some science actions due to potential conflicts of interest. Other factors are external, for example, decision-maker protocols and priorities, data ownership and disclosure issues, and stake-holder requirements. The seven case studies show that: (i) not all relevant science will be solicited by and provided to decision- 
makers through formal channels, such as science advisory panels and other expert elicitation processes; (ii) not all decision-makers will seek all (or even any) potential sources of scientific evidence; (iii) not all solicited and provided science will be fully characterised, understood and utilized in the decisionmaking process; and (iv) not all scientifically-informed decision-making will result in a decision that aligns with prevailing scientific evidence. The subject diversity of the case studies, while not exhaustive, suggests that the actions common to all the case studies are likely to be required by science providers and decision-makers in any scenario. The list shown in Figure 1 provides a prompt for stakeholders during the planning or initial stages of a scenario for actions and pathways that are likely required. This prompt is in contrast to a situation where these actions and pathways are discovered (possibly too late) while a scenario is in progress. Endevoring towards a goal of effective team communication, whereby team members understand the needs of other members and so provide (unsolicited) information via implicity supply (Owen et al. 2013), may also increase the utility of science advice in decision-making (Actions 10, 12, 14; Figure 1). Information provision can be improved through relationship building, via workshops, shared experience, protocol development and training, prior to an event; or through adequate regular briefing and discussions of needs within an event if time permits (Doyle and Paton, 2018 Doyle et al. 2015)

There are many encouraging aspects to be taken from the case studies. Overall, consistent messaging can be achieved as seen by some actions being common across the studies despite their diversity. Eight actions are common to each study (frequency $=7$ ) and can be considered as likely actions when planning a strategy. S1a included the involvement of science experts in risk assessments from diverse institutions with diverse science expertise. Science provider relationships existing prior to the stimulating event enabled efficient data collection. Pre-existing pathways between science providers and government allowed for direct science communications to decision-makers. Processes allowed for the acceptance of initially unsolicited science into decisionmaking processes through multiple and diverse pathways. Precautionary decisions aligned with prevailing science evidence but had adaptive capacity (where possible) should other relevant scientific and non-scientific inputs emerge. S2 demonstrates that it is possible for science providers to communicate risk successfully to a sizeable and diverse industry, even when the decision-makers are geographically distributed. S3 demonstrates that decision-makers want to understand how uncertainty has been accounted for in scientific advice. S4 highlights that it is possible for a diverse range of expert science providers and decision-makers to come together to identify and assess priority emergency risks collaboratively.

In relation to S5, the Environmental Protection Authority recently awarded consent for deep-sea mining to another company called Trans-Tasman Resources who were seeking to mine iron sands from it's South Taranaki Bight iron sands project located $25 \mathrm{~km}$ offshore from Patea on the east coast of the North Island of New Zealand. Consent was granted conditional on two ad- 
ditional years of scientific and environmental monitoring and reporting prior to mining activities commencing 7 . However, the decision was quashed in an appeal to the High Court of New Zealand, which found the decision-makers applied a "narrow interpretation" to the term "adaptive management", which was inconsistent with the intended legal definition 8 . This shows that precautionary adaptive management approaches might find useful balances among contrasting inputs, but that linguistic uncertainty around the precise (legal) meaning of critical words and phrases makes it possible to argue on points of law, which may or may not lend strength to the utility of science evidence in the decision-making process for seabed mining consent applications. S6 demonstrates that science providers are helping to guide decision-makers in resource exploration programmes, particularly with respect to their communication of uncertainties. In relation to S7, incorporation of scientific uncertainty into future GBR report cards is now being discussed, as well as the potential to explore the development of methodologies for quantifying and communicating uncertainty to stakeholders for decision-making.

Just as all science is uncertain and imperfect (Sutherland et al., 2013), so too are all decision-making processes, even those where science is well provided and utilized. This study attempts to provide the scientific community with a sample of the diverse and complex roles and utilities of science in the decisionmaking environment. Endeavours to advance any of the actions and pathways described herein are welcomed and indeed necessary if the emerging challenges of post-truth, unobjectively-tested decision-making are to be met.

Acknowledgements The modelling conducted in case study 2 and analysis activities reported, and the development of the armonline.com.au tools were made possible through funding provided by the Queensland Department of Agriculture and Fisheries under the Department of Agriculture and FisheriesUniversity of Southern Queensland Broad Acre Grains Partnership. Dr Lance Pedergast (Senior Development Agronomist with the Queensland Department of Agriculture and Fisheries) assisted in the design, analysis and communication of chickpea analysis presented in this case study. Mr Howard Cox (Senior Agronomist Department of Agriculture and Fisheries) has contributed to the design and development of the ARM online tools. The author of case study 5 (PD) would like to thank Ray Wood and Renee Grogan for discussing many aspects of the CRP application and EPANZ hearing and decision. Their comments and suggestion greatly improved the original document. Hamish Campbell is also acknowledged for providing a thorough review of the draft.

The paper benefited from a highly thoughtful review by Emma Hudson-Doyle and two anonymous reviewers. We thank Igor Linkov for the professional editorship of the manuscript.

7 See: https://www.epa.govt.nz/assets/Uploads/Documents/Marine-Activities-EEZ/ Activities/TTRL-Marine-Consent-Decision-EEZ000011-FINAL-version.pdf and https://www.ttrl.co.nz/fileadmin/user_upload/TTR_Media_Statement_DMC_Decision_ 10Aug17.pdf

8 See https://www.courtsofnz.govt.nz/cases/the-taranaki-whanganui-conservationboard-v-the-environmental-protection-authority/@@images/fileDecision?r=222.009077804 


\section{References}

Aspinall W (2010) A route to more tractable expert advice. Nature 463:294295

Aven T, Renn O (2010) Risk management. In: In Risk Management and Governance, Springer, Berlin, Heidelberg, pp 121-158

Brownson R, Fielding J, Maylahn C (2009) Evidence-based public health: A fundamental concept for public health practice. Annu Rev Publ Health 30:175-201

Cash DW, Borck JC, Patt AG (2006) Countering the loading-dock approach to linking science and decision making: comparative analysis of el nio/southern oscillation (enso) forecasting systems. Sci Technol Hum Val 31(4):465-494

Colyvan M, Kitto K, Quigley M, Bennetts L, Durance P, Galton-Fenzi B, Geenens G, Hamilton K, Ickowicz A, Killedar M, Kuhnert P, Lindsay M, Pembleton K, Roberts M, Verdejo-Garcia A, White C (2017) Addressing Risk in Conditions of Uncertainty, Ignorance, and Partial Knowledge . In: An interdisciplinary approach to living in a risky world. Recommendations from the Theo Murphy High Flyers Workshop, pp 5-7

Dilling L, Lemos MC (2011) Creating usable science: Opportunities and constraints for climate knowledge use and their implications for science policy. Global Environ Chang 21(2):680-689

Doubleday R, Wilsdon J (2012) Science policy: Beyond the great and good. Nature 485:301-202

Doyle EE, Johnston DM, Smith R, Paton D (2019) Communicating model uncertainty for natural hazards: A qualitative systematic thematic review. International Journal of Disaster Risk Reduction 33:449 - 476, DOI https: //doi.org/10.1016/j.ijdrr.2018.10.023, URL http://www.sciencedirect. com/science/article/pii/S2212420918306630

Doyle EEH, Paton D (2018) Decision-Making: Preventing Miscommunication and Creating Shared Meaning Between Stakeholders, Springer International Publishing, Cham, pp 549-570. DOI 10.1007/11157_2016_31, URL https: //doi.org/10.1007/11157_2016_31

Doyle EEH, Paton D, Johnston DM (2015) Enhancing scientific response in a crisis: evidence-based approaches from emergency management in new zealand. Journal of Applied Volcanology 4(1):1, DOI 10.1186/ s13617-014-0020-8, URL https://doi.org/10.1186/s13617-014-0020-8

Dudo A, Besley J (2016) Scientists prioritization of communication objectives for public engagement. PLoS ONE 11:e0148867

Feldman IHM D L (2009) Making science useful to decision makers: climate forecasts, water management, and knowledge networks. Weather Clim Soc $1(1): 9-21$

Fischoff B, Davis A (2014) Communicating scientific uncertainty. P Natl Acad Sci 111:13664-13671

Foster K, Vecchia P, Repacholi M (2000) Science and the precautionary principle. Science 288:979-981 
Frodeman R (1995) Geological reasoning: Geology as an interpretive and historical science. Geol Soc Am Bull 107:960-968

Gillieson D (2004) Submission to the alpine grazing taskforce, victoria. Tech. rep., Australian Academy of Science

Gluckman P (2014) Policy: The art of science advice to government. Nature 507:163

Gluckman P (2016) Making decisions in the face of uncertainty: Understanding risk. Tech. rep., Office of the Prime Ministers Chief Science Advisor, Auskland, New Zealand

Haasnoot M, Kwakkel JH, Walker WE, ter Maat J (2013) Dynamic adaptive policy pathways: A method for crafting robust decisions for a deeply uncertain world. Global Environ Chang 23(2):485-498, DOI https://doi.org/10. 1016/j.gloenvcha.2012.12.006

Kapucu N, Garayev V (2011) Collaborative decision-making in emergency and disaster management. Int J Pub Admin 34(6):366-375

Karr J (2006) When governments ignore science, scientists should speak up. BioScience 56:287-288

King A, Middleton D, Brown C, Johnston D, Johal S (2014) Insurance: its role in recovery from the 2010-2011 Canterbury earthquake sequence. Earthq Spectra 30:475-491

Kirchhoff CJ, Lemos MC, Dessai S (2013) Actionable knowledge for environmental decision making: broadening the usability of climate science. Ann Rev Env Resour 38:393-414

Krupnick A, Morgenstern R, Batz M, Nelson P, Burtraw D, Shih JS, McWilliams M (2006) Not a sure thing: Making regulatory choices under uncertainty. In: Resources for the Future, Washington, DC

Langer L, Tripney J, Gough D (2016) The science of using science: Researching the use of research evidence in decision-making. Tech. rep., University College London

Lorenzoni I, Nicholson-Cole S, Whitmarsh L (2007) Barriers perceived to engaging with climate change among the UK public and their policy implications. Global Environ Chang 17:445-459

Mackey B, Quigley M (2014) Strong proximal earthquakes revealed by cosmogenic 3he dating of prehistoric rockfalls, Christchurch, New Zealand. Geology 42:975-978

Massey C, McSaveney M, Taig T, Richards L, Litchfield N, Rhoades D, McVerry G, Lukovic B, Heron D, Ries W, Van Dissena R (2014) Determining rockfall risk in Christchurch using rockfalls triggered by the 2010-2011 Canterbury Earthquake Sequence. Earthq Spectra 30:155-181

Mervis J (2017) Trump's 2018 budget proposal 'devalues' science. Science 355:1246-1247

Nisbet M, Markowitz E (2015) Understanding public opinion in debates over biomedical research: Looking beyond political partisanship to focus on beliefs about science and society. PLoS ONE 9:e88473

North DW (1968) A tutorial introduction to decision theory. IEEE T Sys Sci Cyb 4(3):200-210 
Nutbeam D, Boxall A (2008) What influences the transfer of research into health policy and practice? observations from England and Australia. Public Health 122:747-753

Owen C, Bearman C, Brooks B, Chapman J, Paton D, Hossain L (2013) Developing a research framework for complex multiteam coordination in emergency management. International Journal of Emergency Management 9(1):1-17, DOI 10.1504/IJEM.2013.054098, URL https://www . inderscienceonline.com/doi/abs/10.1504/IJEM.2013.054098

Pielke Jr RA (2003) The role of models in prediction for decision. In: Canham CD, Cole JJ, Lauenroth WK (eds) Models in ecosystem science, Princeton University Press, Princeton and Oxford, chap 7, pp 111-135

Pielke Jr RA, Conant RT (2003) Best practices in prediction for decisionmaking: lessons from the atmospheric and earth sciences. Ecology 84:1351-1358

Quigley MC, Bennetts LG, Durance P, Kuhnert PM, Lindsay MD, Pembleton KG, Roberts ME, White CJ (2019) The provision and utility of science and uncertainty to decision-makers: earth science case studies. Environment Systems and Decisions DOI 10.1007/s10669-019-09728-0, URL https:// doi.org/10.1007/s10669-019-09728-0

Reardon S, Tollefson J, Witze A, Ross E (2017) US science agencies face deep cuts in trump budget. Nature 543:471-472

Schaal B (2017) Informing policy with science. Science 355:435

Science Council of Japan (2013) Code of conduct for scientists - revised version. URL http://www.scj.go.jp/en/report/Code_of_Conduct_for_ Scientists-Revised_version.pdf, english version, translated from the original Japanese version

Seeger M (2006) Best practices in crisis communication: An expert panel process. J Appl Commun Res 34:232-244

Speirs-Bridge A, Fidler F, McBride M, Flander L, Cumming G, Burgman M (2010) Reducing overconfidence in the interval judgments of experts. Risk Analysis 30(3):512-523, DOI 10.1111/j.1539-6924.2009. 01337.x, URL https://onlinelibrary.wiley.com/doi/abs/10.1111/j. 1539-6924.2009.01337.x

Sutherland W, Spiegelhalter D, Burgman M (2013) Twenty tips for interpreting scientific claims. Nature 503:335-337

Van Asselt MB, Renn O (2011) Risk governance. J Risk Res 14(4):431-449

Varis O (1997) Bayesian decision analysis for environmental and resource management. Environ Modell Softw 12(2-3):177-185

White C, Remenyi T, McEvoy D, Trundle A, Corney S (2016) 2016 tasmanian state natural disaster risk assessment: All hazard summary. Tech. rep., University of Tasmania

White DJ (2018) Decision theory. Routledge

Whitmer A, Ogden L, Lawton J, Sturner P, Groffman P, Schneider L, Hart D, Halpern B, Schlesinger W, Raciti S, Bettez N (2010) The engaged university: Providing a platform for research that transforms society. Front Ecol Environ 8:314-321 
Zhou L, Wu X, Xu Z, Fujita H (2018) Emergency decision making for natural disasters: An overview. International journal of disaster risk reduction $27: 567-576$ 